\title{
Laser Powder Bed Fabrication of Nickel-Base Superalloys: Influence of Parameters; Characterisation, Quantification and Mitigation of Cracking
}

\author{
Luke N. Carter ${ }^{1}$, Moataz M. Attallah ${ }^{1}$, Roger C. Reed ${ }^{1}$ \\ ${ }^{1}$ School of Metallurgy and Materials, University of Birmingham, Edgbaston, Birmingham, B15 2TT, UK. \\ (*Corresponding author: Email: M.M.Attallah@Bham.ac.uk; Telephone: (+44) 121414 7842)
}

Keywords: Selective Laser Melting, Ni-based Superalloys, Microstructure Alloy Index Keywords: CM247LC

\begin{abstract}
The use of a selective laser melting (SLM) powder-bed method to manufacture Ni-based superalloys components provides an economic approach for low production run components that operate under a high-temperature and stress environment. A major concern with the SLM of precipitation hardenable Ni-based superalloys is their high susceptibility to cracking, which has been heavily documented in the field of welding. Weld cracking may occur either during processing (hot cracking, liquation cracking and ductility-dip cracking) or during the post weld heat-treatment stage (strain-age cracking). Due to the complex thermal history of SLM fabricated material there is the potential for all of these mechanisms to be active.

In this investigation, cuboidal coupons of the Ni-based superalloy CM247LC were fabricated by the SLM of argon gas atomised powder. Parametric studies were performed to investigate the influence of the process parameters (laser scan speed, power and scan spacing) on the cracking density and morphology through conducting a stereological study of scanning electron microscope (SEM) micrographs. Further microstructural evidence is presented, illustrating the different crack morphologies observed as well as suggesting the responsible mechanisms. Finally a postfabrication Hot Isostatic Pressing (HIP) treatment was performed to investigate its utility in 'healing' the internal cracks, and providing a route to retro-fix the cracking problem in the heat treatment stage of production. The findings highlight the need for process models of the SLM method in order to understand the thermal history and the laser fabricated structures observed.
\end{abstract}

\section{Introduction}

The discipline of additive layer manufacture (ALM) has been steadily growing since the 1980's and now encompasses a wide variety of technologies. They all share the common feature of producing a three dimensional shape by combining two dimensional 'slices' of a predetermined thickness. In recent years, ALM technologies have been developed to push the field forward from 'rapid-prototyping' towards 'rapid-manufacturing' and the production of fully dense and functional metallic components. In terms of laser fabrication there are now two key technologies for the rapid manufacture of fully-dense metallic components; Direct Laser Fabrication (DLF or any 'Blown Powder' system) and 'Selective Laser Melting (SLM) Powder-Bed' manufacturing. Comprehensive reviews of the different ALM methods can be found elsewhere [1-4].

SLM powder-bed technology has attracted the interest of aerospace manufacturers for several key reasons including: The elimination of the need the expensive tooling associated with forging and investment casting; the immediate recyclability of the unused metal powder, and the significant reduction in the 'design-to-component' time thus allowing for actual physical testing and many design iterations. The present study aims to assess the microstructural and physical characteristics of the SLM fabricated Ni-based superalloy for high-temperature application.

\section{Weld Cracking}

Laser fabrication process can be considered analogous to a continuous laser welding process. Due to this, an alloy weldability can be used as an indication as to its processability by SLM. Figure 1 [5] shows a number of typical Ni-based superalloys plotted according to their $\mathrm{Al}$ and $\mathrm{Ti}$ contents $\left(\gamma^{\prime}\right.$ forming elements). The alloys lying above the dotted line show a high volume fraction of the $\gamma^{\prime}$ phase and are typically considered unweldable due to their cracking susceptibility. This relationship between the cracking susceptibility and $\gamma^{\prime}$ fraction is attributed to the precipitation hardening that occurs within the aging temperature of the alloy; reheating the material to within this region (either in the welding process or as part of a post-weld heat treatment (PWHT)) results in hardening accompanied by a reduction in ductility leaving the material prone to cracking [5]. A review of the relevant literature highlighted four potential cracking mechanisms associated with welding and reheating of Ni-based superalloys, which are:

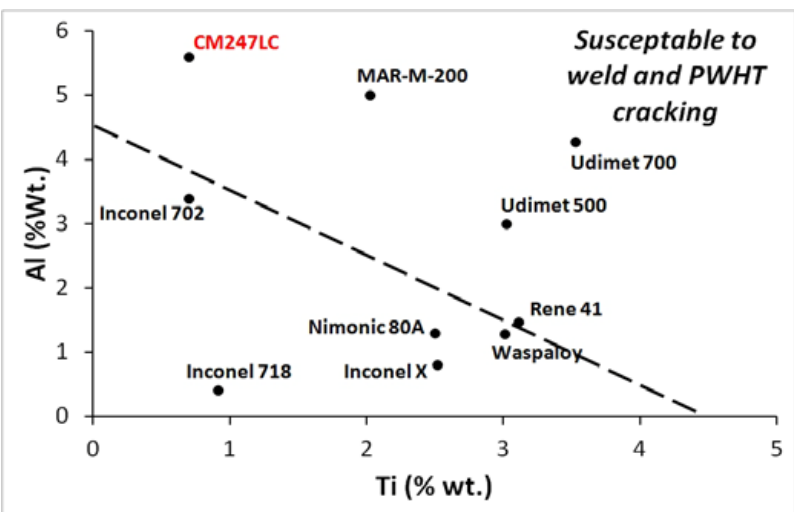

Figure 1. Plot showing increasing cracking susceptibility with $\gamma^{\prime}$ forming elements (Al and $\mathrm{Ti}$ ) [5]. Alloys lying above the dotted line are particularly susceptible to cracking during welding or PWHT.

Solidification Cracking

Also referred to as 'Hot-Tearing', is reported to occur within the solidifying melt pool (or the mushy zone) where the material is in 
a partially solid state [5-7]. During the solidification, dendrite formation inhibits the flow of the remaining liquid in the interdendritic regions [8]. The remaining liquid regions can act as crack initiation points under the influence of the stress induced by solidification. This mechanism of weld cracking is not restricted to Ni-based superalloys, as it can be found in other alloy systems.

\section{Liquation Cracking}

Welding literature presents this mechanism as the cause of cracking under lower-energy welding conditions[8]. Liquation cracking is generally reported to occur in a location away from the melt pool where the bulk material is heated rapidly to a temperature which is lower than the overall liquidus of the material [8]. This rapid heating has been reported to cause melting of certain grain-boundary phases such as the $\gamma-\gamma^{\prime}$ eutectic and lowmelting point carbides [9-12]. Under the large residual stresses formed during the laser deposition, these liquid films have the potential to act as crack initiation points forming grain-boundary cracks in the fabricated material.

\section{Strain-age cracking (SAC)}

Associated with a PWHT of nickel superalloys, SAC may occur when the welded material is reheated to within the ageing region either as part of a stress-relief or during the ramp phase of a solution treatment [5]. The repeated reheating of the SLM fabricated material with the deposition of each subsequent layer leaves it potentially vulnerable to this form of cracking. During a PWHT two competing actions occur; the desired relaxation of residual stresses occurs slowly when compared to the further precipitation of the $\gamma^{\prime}$ phase. This ageing process increases the material strength whilst reducing ductility [5, 12]. The superposition of the remaining residual stress and a further induced stress from the precipitation of the $\gamma^{\prime}$ from solid solution [13] can result in a strain that exceeds the limited ductility of the material. Material failure typically occurs at grain boundaries with carbides acting as crack initiation points [12].

Ductility-dip cracking (DDC)

DDC is an ambiguous term within literature, often being grouped with SAC in the blanket terms of 'reheat cracking' or 'hot cracking' although recent work has established DDC as a separate pheneomenon [6]. DDC relates to the phenomenon of a marked reduction in ductility (the 'ductility-dip') in Ni-based alloys under intermediate temperature conditions [6,14]. The majority of the relevant literature refers to DDC within weld filler materials; however a study by Kim et al. [15] presents mechanical data for CM247LC showing a reduction in ductility occurring between $700^{\circ} \mathrm{C}$ and $900^{\circ} \mathrm{C}$.

The microstructural mechanisms of DDC are the subject of debate in literature with two differing mechanisms being suggested. Lippold and co-workers [14, 16-19] suggested that DDC is a 'creep-like' mechanism acting in a temperature range high enough to accommodate grain-boundary sliding but below the threshold for dynamic recrystallisation [14, 18]. It was concluded that the strain concentrations caused by grain boundary sliding resulted in void formation on grain boundary features. Triple point boundary intersections were found to be particularly vulnerable to stress concentrations; the addition of fine grain boundary particles provided microscopic locking and reduced the void formation at the triple points but resulted in void formation around the particles. The grain boundary morphology also proved important with the more tortuous boundaries showing greater DDC resistance when combined with fine grain boundary precipitates and finally the additional inclusion of larger grain boundary particles combined the effect of macroscopic and microscopic locking with the benefits of tortuous boundaries resulted in the best DDC resistance $[14,16,18]$. Additionally it was found that DDC susceptibility was increased around high angle grain boundaries [16].

The study carried out by Young et al. [20] suggests that DDC occurs by a similar mechanism to SAC and is caused by the precipitation of carbides at grain boundaries. These carbides impose a stress in the surrounding material and can result in voids at the grain boundaries.

Laser Fabrication of Ni-based Superalloys

The majority of literature relating to the laser fabrication of Nibased superalloys examines material processed by a DLF or wirefeed method. The issue of cracking is typically not addressed as much of this research deals with the more easily processed materials of Inconel 718 [21-23] and Inconel 738 [23-25], which either have a lower $\gamma^{\prime}$ fraction or the slower precipitating $\gamma^{\prime \prime}$ phase, thus reducing the susceptibility for weld cracking.

The growth of elongated columnar grains across several build layers due to the 'heat sink' effect imposed by the build plate or substrate has been documented in both methods of laser fabrication of Ni-based superalloys; widely in literature relating to DLF [21, 22, 25-29]. Epitaxial growth of grains across build layers has also been reported in SLM powder-bed literature [30]. It has been recognised that this feature, if refined, has the potential to mimic a DS casting, providing enhanced material properties in the build direction. Work carried out by Gaumann et al. [29] showed that the onset of grain elongation could be mapped to the processing conditions.

In addition to the grain structure, the $\gamma^{\prime}$ structure of laser deposited material has been shown to be quite different to that of a conventionally formed material. Several authors have reported a limited precipitation of the $\gamma^{\prime}$ phase due to the rapid cooling of the material following deposition [23, 25, 27] and as such will influence the heat treatment required to idealise the microstructure for functional use.

The presence of residual stress in laser fabricated Ni-based superalloys poses a significant area of interest with studies being carried out into measurement [21, 31] and modeling [32].

Previous work concerning a SLM powder-bed fabricated Ni-based superalloy has been carried out by Wu et al. [33] which relates the parameters to dimensional accuracy, surface finish, density and cracking of Hastelloy X. The mechanical properties of the optimised material were assessed and found to be comparable to those of the forged samples.

\section{Post-Fabrication Hot Isostatic Pressing HIP Treatment}

The application of a HIP treatment following casting has been shown to reduce the internal porosity of a cast nickel superalloy CMSX-4 [34]. This technique has been applied previously to a SLM fabricated nickel alloy in the work presented by Wu et al. [33] (Hastelloy X) and also that of Zhao et al. [35] (Rene 88DT) in order to 'heal' internal cracking of the material and improve the mechanical properties.

The current investigation focuses on the cracking phenomenon within the SLM fabricated material; its characterisation and quantification with respect to the processing conditions. Finally it 
examines the possibility of mitigating the cracking through the utility of a 'retro-fix' post-fabrication HIP treatment.

\section{Experimental}

Material

CM247LC was selected for this study based on its high temperature capabilities as a directionally-solidified (DS) turbine blade material. In a DS cast and ideally heat-treated condition, the alloy will maintain a UTS of approximately $1200 \mathrm{MPa}$ up to temperatures of $800^{\circ} \mathrm{C}$ [36]. Table 1 [37] shows the nominal and measured chemical composition (using inductively coupled plasma) of the supplied material. CM247LC is a slightly modified version of the more traditional MAR-M247 with a lower carbon content and tighter controls on the detrimental elements Si and S [38]. The material is a $\gamma^{\prime}$-precipitation strengthened Ni-based superalloy developed for use in high-temperature aero-engine application. When the alloy is heat-treated following casting , the ideal cuboidal form of the $\gamma^{\prime}\left(\mathrm{Ni}_{3} \mathrm{Al}\right)$ structure allows for a creep life of $2000 \mathrm{~h}$ at $150 \mathrm{MPa}, 950^{\circ} \mathrm{C}$ [39]. Grain-boundary strengthening is provided by the formation of carbides, facilitated by the addition of Hf [40], which has also been associated with a reduction in susceptibility to hot tearing during casting [41].

Table 1. Nominal chemical composition of CM247LC (\%wt.) [37] compared against Incotest analysis of LPW Ltd. supplied CM247LC powder.

\begin{tabular}{|c|c|c|}
\hline & Nominal & Measured \\
\hline C & 0.07 & 0.066 \\
\hline $\mathrm{Cr}$ & 8 & 0.81 \\
\hline $\mathrm{Ni}$ & Bal. & Bal. \\
\hline Co & 9 & 9.22 \\
\hline Mo & 0.5 & 0.49 \\
\hline W & 10 & 10.3 \\
\hline Ta & 3.2 & 3.32 \\
\hline $\mathbf{T i}$ & 0.7 & 0.72 \\
\hline Al & 5.6 & 5.8 \\
\hline B & 0.015 & 0.018 \\
\hline $\mathrm{Zr}$ & 0.01 & 0.012 \\
\hline Hf & 1.4 & 1.4 \\
\hline $\mathrm{Si}$ & $\leq 0.03$ & 0.04 \\
\hline S & $\leq 15 p p m$ & $<0.001$ \\
\hline $\mathbf{P}$ & N/A & 0.006 \\
\hline $\mathbf{F e}$ & N/A & $<0.01$ \\
\hline Mg & N/A & $<0.001$ \\
\hline $\mathbf{N}$ & N/A & 0.003 \\
\hline $\mathbf{O}$ & N/A & 0.007 \\
\hline
\end{tabular}

\section{CM247LC Powder}

Argon gas atomised CM247LC powder was supplied by LPW Technology Ltd. in the size fraction $+15-53 \mu \mathrm{m}$, which is the ideal size range for SLM, as the powder of this size range spreads well in the SLM process. A sample of the powder was ground and examined using SEM microscopy and showed a regular equiaxed grain structure and no noticeable segregation in the backscattered electron (BSe) image or following energy dispersive x-ray (EDX) analysis. The internal porosity of the powder was calculated using image analysis of SEM micrographs to be $0.9 \%$.
Powder-Bed Laser Fabrication

All SLM fabricated samples were processed using the 'Concept Laser M2 Cusing Laser Powder-Bed' system located in the School of Metallurgy and Materials at the University of Birmingham. The M2 system has a maximum build area of 250 $\mathrm{mm} \times 250 \mathrm{~mm}$ and a maximum build height of $300 \mathrm{~mm}$. The M2 facility is typical of a SLM powder-bed system, as shown schematically in Figure 2. A sequence of operation can be found elsewhere [1].

SLM is performed on the M2 by a continuous wave fibre laser with a variable output (maximum 200W) capable of scanning across the build platform at a maximum speed of $7000 \mathrm{~mm} / \mathrm{s}$. Resolution in the $\mathrm{X}-\mathrm{Y}$ direction is limited by the laser spot size which is fixed at $150 \mu \mathrm{m}$ and all builds were carried out using a $20 \mu \mathrm{m}$ slice thickness (Z-increment). Processing was performed in an Argon atmosphere, with oxygen levels maintained at $<0.1 \%$.

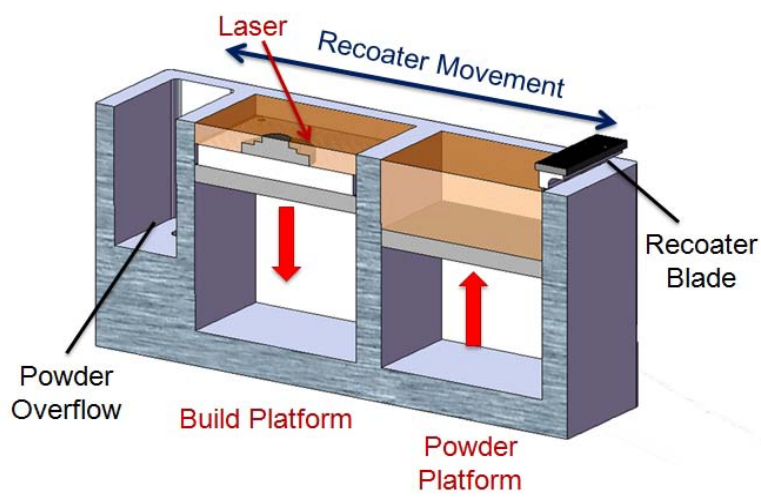

Figure 2. Schematic representation of the Concept Laser M2 Powder Bed Laser Cusing ${ }^{\circledR}$ facility. Each subsequent layer of powder is spread over the build area by the movement of the recoater blade and then selectively melted using the computer controlled laser.

A scan regime was selected to best represent how the machine would be operated in a manufacturing situation. Under this regime, the filled area to be raster scanned is divided into small squares or 'islands'. Within each island, the laser spot is scanned in a single direction, but perpendicular to the direction of the laser scan within the islands lying next to it. These islands are selectively melted in a random order in an attempt to evenly distribute the heating, and so reduce the residual stresses. Following the selective melting of the islands, the laser is scanned around the outer-contour of the slice to refine the surface finish of the fabricated part; Figure 3. For each subsequent layer, the pattern of islands (often referred to as the 'chessboard') is moved by $1 \mathrm{~mm}$ in both the $\mathrm{X}$ and $\mathrm{Y}$ directions thus varying the scan directions over the build height. This differs to the more conventional scan regimes where the entire slice is subject to a uniform or 'cross-hatching' scan pattern [42].

An array of cubical samples, each measuring $10 \mathrm{~mm}(\mathrm{X}) \times 10$ $\mathrm{mm}(\mathrm{Y}) \times 20 \mathrm{~mm}(\mathrm{Z})$, was SLM fabricated to assess the influence of the process parameters on the cracking density. The parameters for laser power (P) \& scan speed $(v)$ parameters of the raster fill area were varied, whilst all other parameters and conditions were kept constant. The samples were vertically offset by $5 \mathrm{~mm}$ from 
the build plate and supported using thin walled supports for ease of removal and in an aim to homogenise the microstructure by reducing the heat-sinking effect of the build plate. This is a fairly standard practice in SLM .

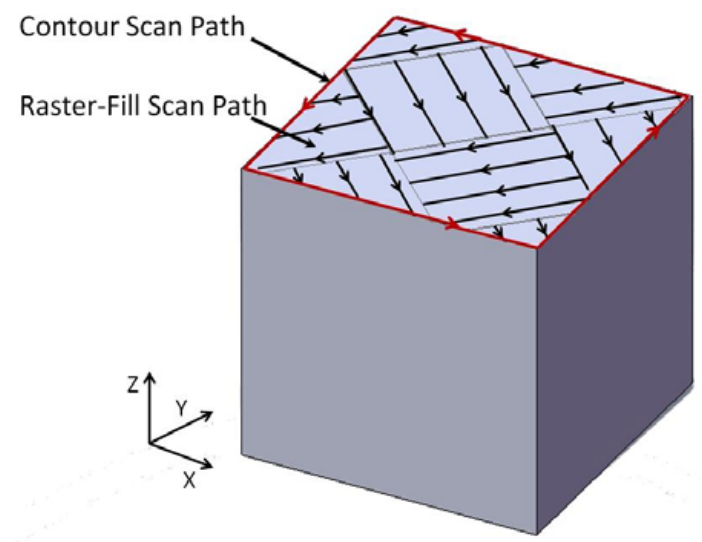

Figure 3. Schematic representation of the laser scanning regime for each layer; The raster filled area is scanned in $5 \mathrm{~mm} \times 5 \mathrm{~mm}$ 'islands', this 'chess-board' pattern moves by $1 \mathrm{~mm}$ in both $\mathrm{X}$ and $\mathrm{Y}$ with each layer. The contour is scanned following the raster fill.

Figure 4 shows this array in the as fabricated condition still attached to the build plate. Following the examination and quantification of the cracks further samples were fabricated varying the scan spacing $(h)$ in the raster fill area whilst keeping laser power and scan speed constant. This was carried out to investigate the effect of scan spacing on the void style of volumetric defects in the low-power samples.

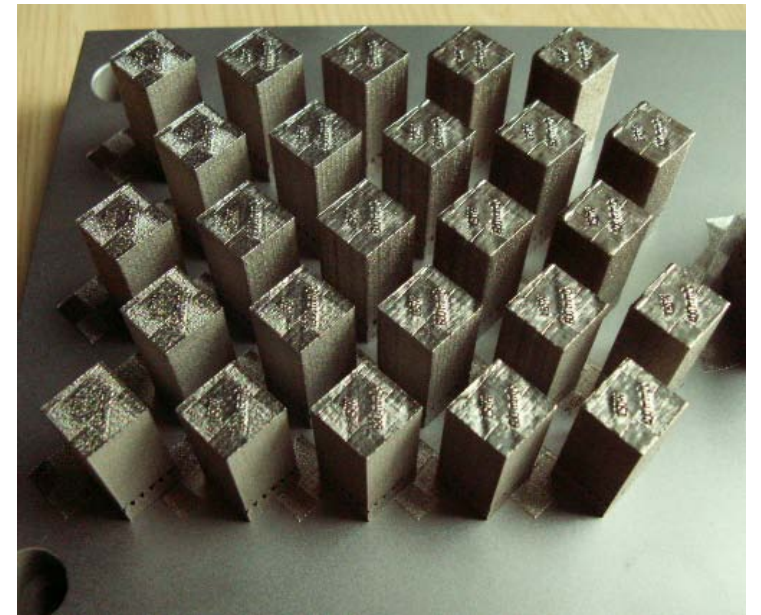

Figure 4. Photograph of matrix of blocks processed with varying scan speeds and laser powers

Due to the proprietary nature of the process parameters, only the normalised values can be disclosed. It can be stated however that the current study investigated a processing window of $100 \mathrm{~W}$ - 200W for laser power (P) and $400 \mathrm{~mm} / \mathrm{s}-2000 \mathrm{~mm} / \mathrm{s}$ for laser scan speed $(v)$. A number of samples produced were abandoned following initial examination as it was decided that it lay too close to other conditions to yield significantly different results. Table 2 shows the normalised process parameters for the analysed samples and qualitative energy levels used. These are provided for the purposes of discussion, based on microstructural observations.

Table 2. The investigated conditions, showing a qualitative energy level for use in discussion

\begin{tabular}{|c|c|c|c|c|c|c|c|}
\hline & \multicolumn{7}{|c|}{ Laser Scan Speed (v) } \\
\hline $\begin{array}{c}\text { Laser Power } \\
\text { Level (P) }\end{array}$ & $v$ & $1.5 v$ & $2 v$ & $2.5 v$ & $3.125 v$ & $3.75 v$ & $5 v$ \\
\hline P1 & & & & & & & \\
\hline P2 & & & & & & & \\
\hline P3 & & & & & & & \\
\hline
\end{tabular}

\begin{tabular}{|c|c|c|c|c|}
\hline Laser Power (P)/Speed Condition (v) & \multicolumn{4}{|c|}{ Scan Spacing (h) } \\
\hline $\mathrm{P} 3 ; 5 v$ & $2.6 h$ & & $1,5 h$ & $h$ \\
\hline $\mathrm{P} 1 ; 3.75 v$ & $2.6 h$ & $2 h$ & $1.5 h$ & $h$ \\
\hline
\end{tabular}

'High-Energy Condition'

'Low-Energy Condition'

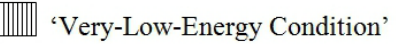

Not Built

Image Analysis, Crack Quantification \& Characterisation Figure 5 illustrates the preparation sequence and image analysis steps used to quantify the cracking density within each sample. The cuboidal samples were sectioned parallel to the build direction revealing the $\mathrm{X}-\mathrm{Z}$ plane to be examined (Figure 5(a)). The samples were then mounted and polished to a $0.05 \mu \mathrm{m}$ oxide finish. Specimens were examined using a Phillips XL-30 (LaB6 source) operated at $20 \mathrm{kV}$ for imaging. Further SEM investigations were performed using a JEOL-7000 Field Emission Gun (FEG)-SEM, equipped with an Oxford INCA electron backscattered diffraction (EBSD) detector, and INCA Crystal software for EBSD acquisition and analysis.

Backscattered electron (BSe) images were collected along two vertical sampling lines; a line running down the centre of the sample in the build direction (Midline) and another running $2 \mathrm{~mm}$ from the edge of the sample in the build direction (Edgeline); as shown in Figure 5(b). This allows for a comparison between the centre and edge regions of the samples. For each of the sampling lines, 30 low-magnification BSe images were collected at $500 \mu \mathrm{m}$ intervals from $2 \mathrm{~mm}$ below the upper surface. The BSe images clearly showed the cracks, aiding the image analysis process (Figure 5(c)). ImageJ [43] image analysis software was used to analyse the crack lengths. A threshold was applied to produce a binary image showing only the cracked areas (Figure 5(d)). Analysis was carried out on the binary image and the maximum feret length of each of the crack segments was recorded (Figure 5(e)). This was summed for each image and normalised with respect to the micrograph area. The mean of these values was calculated for the 30 images in each sampling line, giving a final value of average cracking for the midline and edgeline of each sample. The cracking measurements are therefore recorded using the unit "mm of cracks $/ \mathrm{mm}^{2}$ of micrograph". No metallographic 
(statistical) corrections were employed to account for the sectioning errors, as a sufficient number of images were sampled to comparatively assess the cracking density.

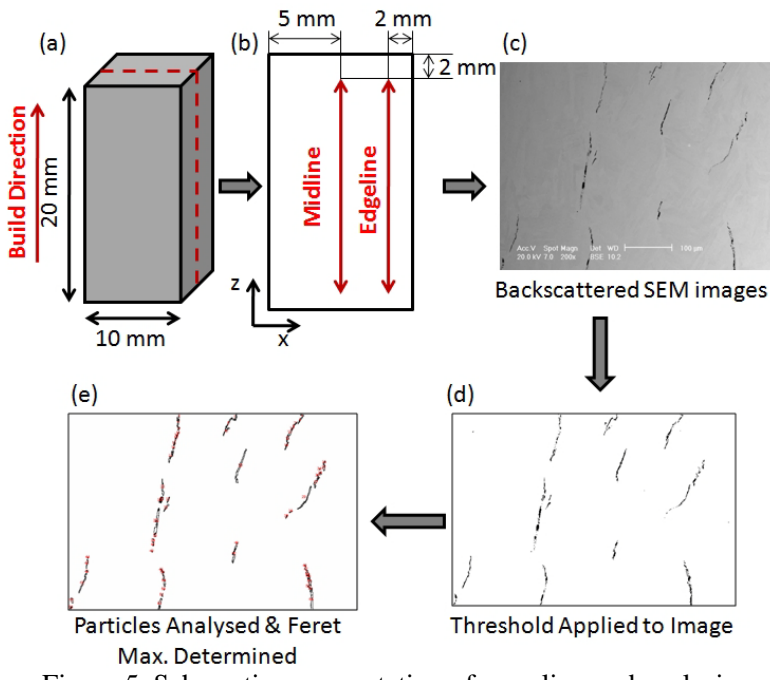

Figure 5. Schematic representation of sampling and analysis method:(a) blocks were sectioned longitudinally (parallel to build direction); (b) 30 images takes along midline and edgeline at $500 \mu \mathrm{m}$ intervals; (c) following standard grinding and polishing, low magnification BSe SEM images reveal cracks; (d) threshold applied to image to isolate cracks; and (e) image analysis carried out to determine feret max. of each crack segment

Post-fabrication HIP Treatment

Following the optimisation of the process parameters, a postfabrication HIP treatment was applied in order to close any remaining cracks as has been previously discussed in the laser fabrication of Hastalloy X [33]. The HIP treatment was carried out in the facility located in the School of Metallurgy and Materials at the University of Birmingham. HIP process conditions were based on those used to fully consolidate a similar SLM fabricated material [33]. The sample was then sectioned and BSe SEM images were taken to evaluate the effectiveness of the HIP in closing any remaining cracks.

\section{Results \& Discussion}

The micrographs presented are representative of those typical for the stated processing conditions. The general phrases used in grouping different energy levels are defined in Table 2 of the experimental section.

\section{Cracking Characterisation}

Microstructural observations revealed that the cracking regimes under different processing conditions appear quite distinctive. In general, the samples can be placed into one of three categories depending on the crack structure observed.

Micrographs taken from a typical 'high-energy' build (P2; 1.5v) are presented in Figure 6. Figure 6(a) shows a low magnification BSe SEM micrograph from the set used to quantify the cracks within the sample; there is a distinct dominance of a 'jagged' cracking morphology. The build direction also relates to the direction of grain elongation as it is characteristically aligned with the flow of heat during the laser fabrication process [30]; conversely the cracks observed here move both longitudinally and transversely to this. Figure 6(b) shows a high magnification micrograph of a typical 'jagged' crack; both of the crack walls show clearly protruding dendritic structures. This is consistent with the formation of solidification cracks as discussed in the introduction.
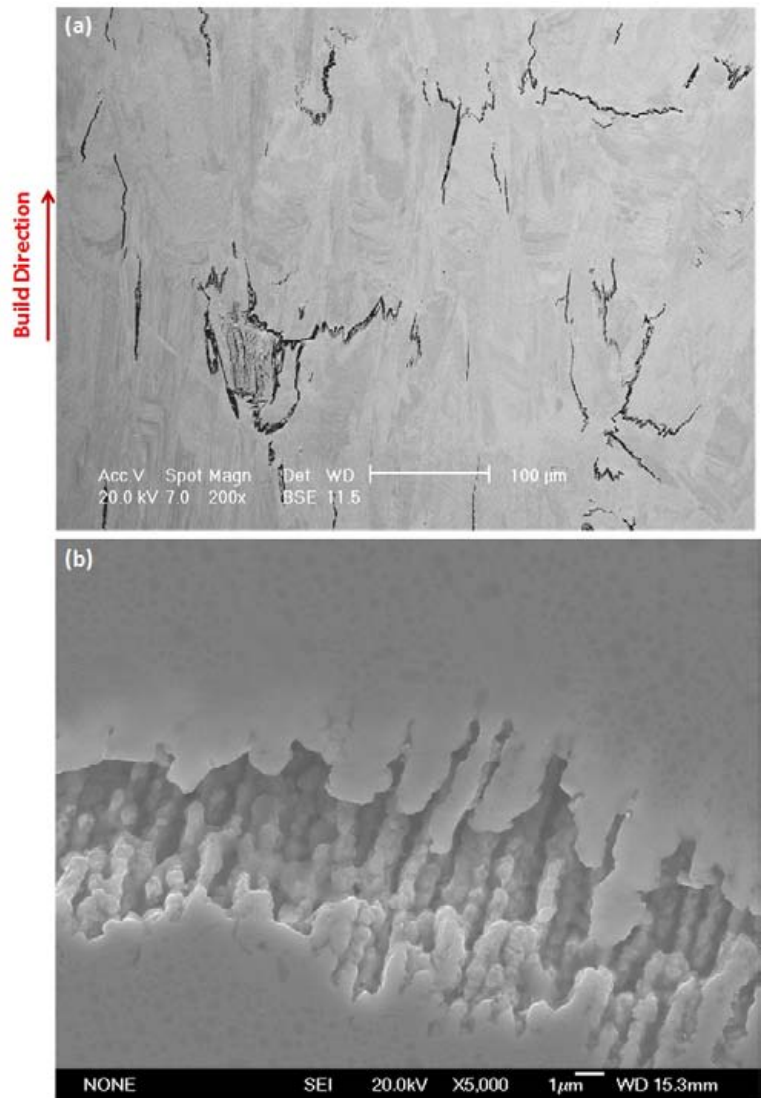

Figure 6. Micrographs showing crack detail in a 'high-energy' build (P2; 1.5v), (a) the dominance of the 'jagged' cracks which show little directionality with respect to the direction of grain growth (build direction). (b) a higher magnification image of a typical 'jagged' crack; note the dendritic growth from either side suggestion the crack has opened during a semi-liquid state typical of a solidification crack.

Micrographs showing the cracks observed within a typical 'lowenergy' (P1; 2.5v) build are presented in Figure 7. Figure 7(a) shows a typical low magnification BSe SEM micrograph from the set used for crack quantification. These cracks show some key differences compared to those observed in the high-energy fabricated samples. There is a clear directionality with the cracks being aligned almost exclusively in the build direction and consequently the direction of grain elongation. Structurally, they appear to be much cleaner and straighter. The high magnification micrograph shown in Figure 7 (b) shows clean smooth crack walls suggesting that the crack was formed during the solid state.

Electron backscattered diffraction (EBSD) mapping of the 'lowenergy’ build cracks (Figure 8(a)) showed that the cracks typically 
lie on grain boundaries. This is supported by the high magnification micrograph in Figure 8(b) showing the crack lying along a line of fine particles, most likely grain boundary carbides.
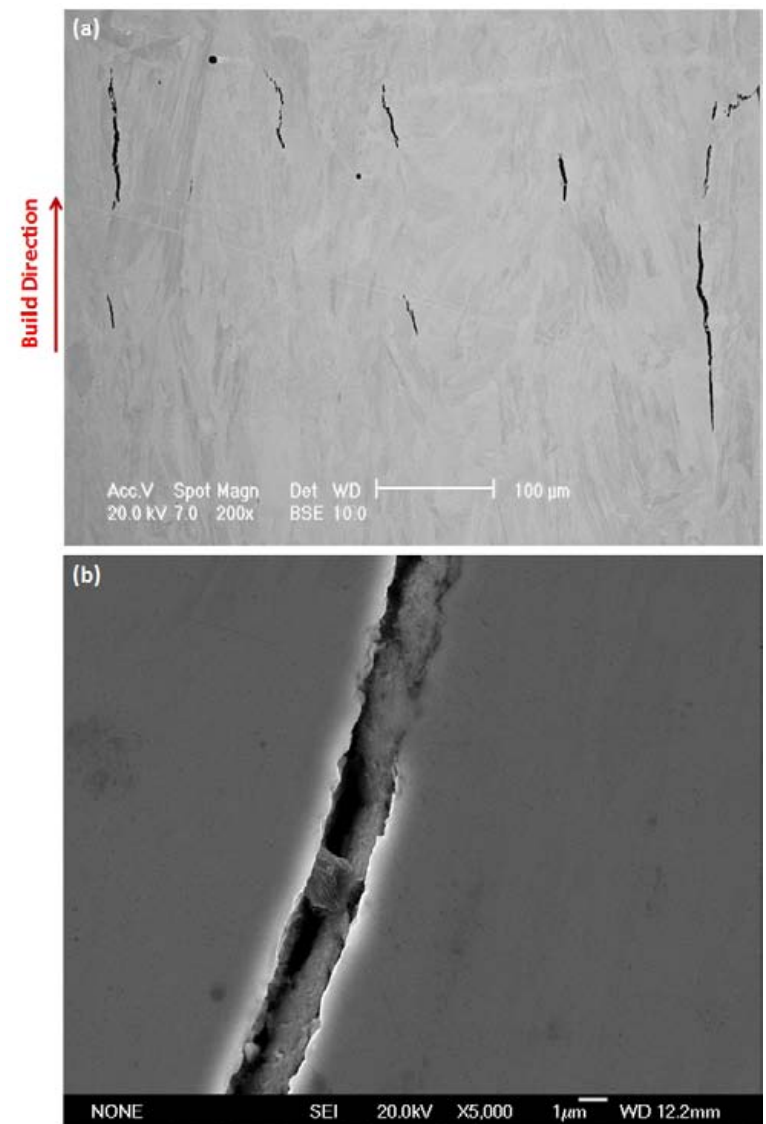

Figure 7. Micrographs showing crack detail in a 'low-energy' build (P1; 2.5v). (a) the dominance of the grain-boundary crack lying dominantly in the build direction. (b) a higher magnification image of a typical grain-boundary crack; note the clean edges indicating that the crack formed in the solid state.
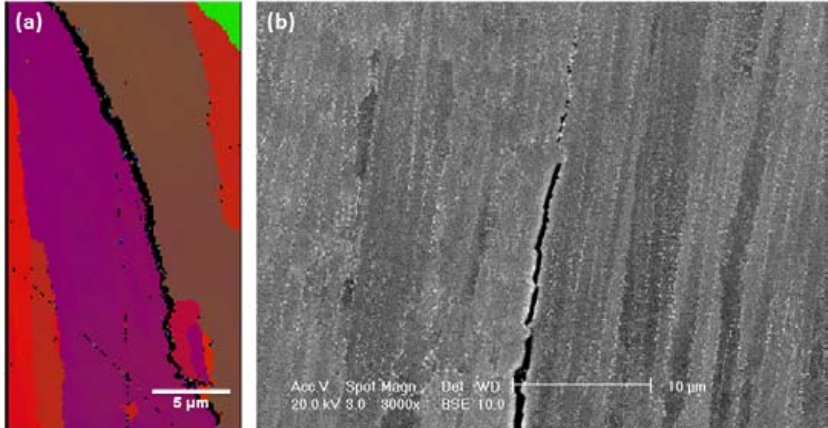

Figure 8. Grain-boundary crack detail: (a) a typical EBSD map of a grain-boundary crack observed in the as-fabricated material. (b) a backscattered SEM micrograph of a similar crack in high magnification; note the fine elongated grains and the particular carbide precipitates along the boundaries including the crack boundary.

Based on the observations that the cracks shown in Figure 7 and Figure 8 have been formed in the solid state and lie at the grain boundaries, three potential cracking mechanisms can be suggested for their formation: Liquation cracking, SAC and DDC. The BSe micrographs have shown no evidence of liquation phases at the grain boundaries and their straight clean character suggests that liquation is not the primary cause of the cracking. The fine carbides observed on the boundaries indicate the possibility of DDC by either of the suggested mechanisms in the literature [18, 20]. At this stage in the investigation however, none of the three mechanisms can be entirely eliminated nor proven; further investigations have been planned in order to establish the primary mechanism or combined mechanisms responsible for these grain boundary cracks.

The final processing region observed occurs under 'very lowenergy' (P1; 3.75v) processing conditions and represents the failure of the process to fully consolidate the powder. The micrograph shown in Figure 9 shows clearly this onset of 'void formation' caused by the shrunken melt-pool under the lowenergy conditions.

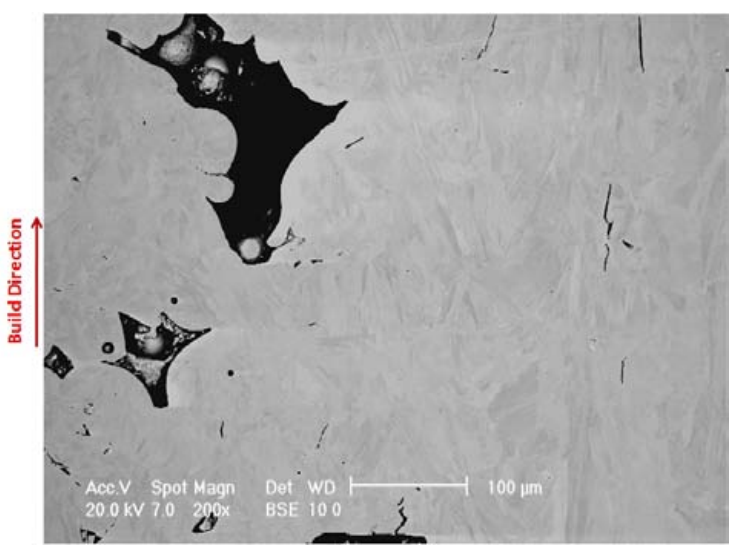

Figure 9. BSe SEM micrograph showing the onset of void formation occurring during a 'very low-energy' build (P1; 3.75v).

This is likely to be caused by a smaller melt pool during processing resulting in incomplete consolidation. 
Cracking Quantification

The cracking quantification results obtained for the midline of the SLM samples are presented in Figure 10. The plots show the variation of cracking with laser scan speed for three different laser powers. All three laser powers show a distinctive drop in cracking level occurring at either the $2 v$ or $2.5 v$ scan speeds; this boundary is represented by the dotted line. When these results are compared against the microstructural observations, it can be seen that the drop in recorded cracking levels coincides with the change in the dominant cracking type; the high-power conditions resulting in solidification cracking and the lower-power conditions resulting in grain-boundary cracking as indicated in Figure 10.

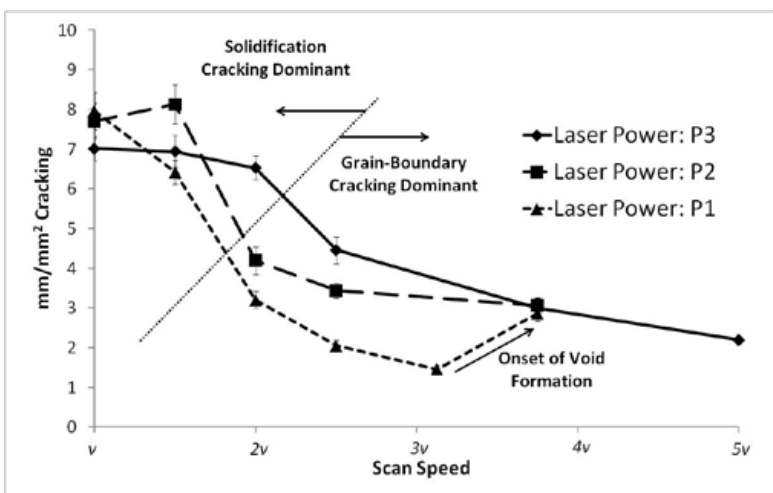

Figure 10. Plot showing the variation of cracking with laser scan speed and power for sample midlines. Arrows indicate the conditions where each of the cracking types is dominant. Note the increase in cracking of the P1 line caused by the onset of void formation

Figure 11 shows the difference in cracking levels between the edgeline of the sample and the midline of the sample for increasing laser scan speeds and three different power levels. These results represent the observed variation in cracking levels across the sample. Under the slower scan speeds, there appears to be no clear trend. However, under the faster scan speeds ( $2.5 \mathrm{v}$ and $3.75 \mathrm{v}$ ), there is a consistently higher cracking level in the middle of the sample when compared to the edge (as represented by the negative values); additionally these processing conditions show a dominance of grain-boundary cracking (as previously discussed). It is clear that the specific thermal history along the midline of the sample therefore leaves it more prone to cracking either due to elevated residual stress or unfavourable heat transfer behaviour.

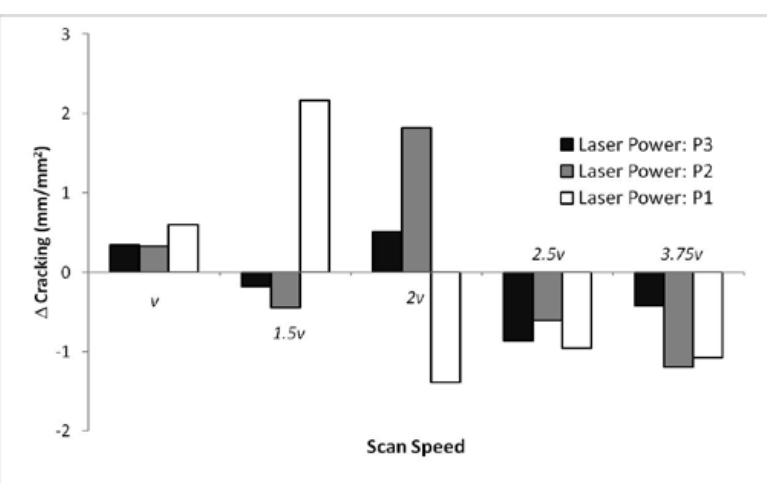

Figure 11. Plot showing $\Delta$ Cracking (Edgeline Cracking - Midline Cracking values) for complete data sets. The lower energy builds (faster scan speeds) show a clear concentration of the grainboundary cracking grouped in the middle of the sample.

The increase in crack density indicated on the plot in Figure 10 relates to void formation (as seen in Figure 9) and does not represent an increase in the cracking level but a limitation of the image analysis method used. The onset of void formation is due to the shrinking of the melt pool under 'very low-energy' conditions, as previously discussed. It was observed however that other than the presence of voids, the amount of cracking in this sample appeared to be relatively low (Figure 9). Therefore, in an attempt to eliminate the voids, the scan spacing $(h)$ was reduced in order to compensate for the shrinking of the melt pool. This scan space reduction was carried out for the laser power and scan speed that initially displayed voids $(\mathrm{P} 1 ; 3.75 \mathrm{v})$ and also for a second parameter set of a greater laser power and faster scan speed (P3; $5 v$ ) in order to see the effect of this scan spacing reduction under conditions where the material had fully consolidated.

The crack quantification results based on the scan spacing reduction are presented in Figure 12. These show that the reduction in scan spacing succeeded in eliminating the voids in the $\mathrm{P} 1 ; 3.75 v$ parameter set; there were no visible voids for that parameter set in the samples produced at scan spacing of $1.5 \mathrm{~h}$ and $h$. However under the higher laser power condition (P3; $5 v)$, the results showed a distinct increase in cracking levels and the micrographs showed an increase in the instances of solidification cracking with the decreasing scan spacing. The exact reason for this remains unknown, however it is suggested that the decreased scan spacing, coupled with the high power, high scan speed conditions produced an effect similar to a 'band' of heat moving slowly across the powder, rather than a rapidly scanning point source which could have facilitated the formation of the solidification cracks. 


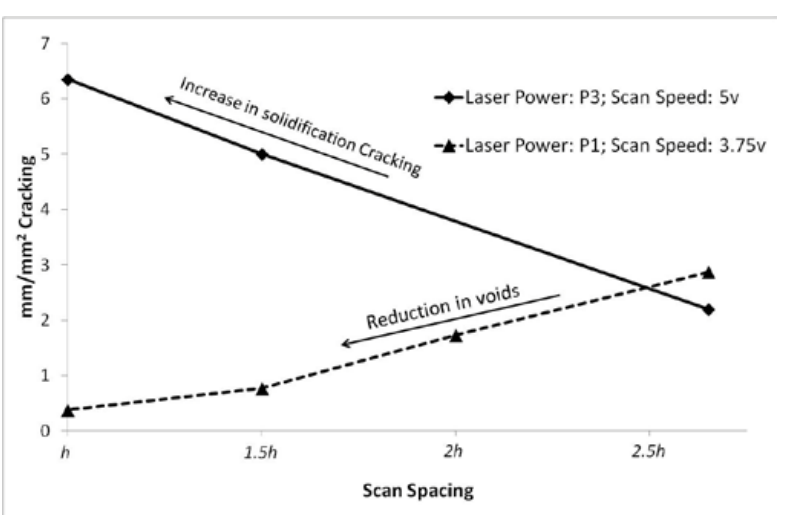

Figure 12. Plot showing the variation of cracking with scan spacing (h). Shows the ability of a reduction in scan spacing to close voids, however in fully dense builds using a higher laser power the instance of solidification cracking appears to be increased with a reduction in scan spacing

\section{Post-fabrication HIP treatment}

Following the crack quantification to establish a set of processing parameters to produce a cracking minimum, a laser fabricated sample was HIP treated in order to close the internal cracks; The HIP treated sample is shown in Figure 13. The internal cracking appears to have fully closed with only some very small isolated porosity remaining. The HIP treatment has also caused the additional precipitation of particulate carbides along the grain boundaries, which can also be seen in the micrograph. It should be emphasised however that this 'retro-fix' solution to the cracking phenomenon is only effective in closing internal cracks and surface connected cracks remain unaffected.

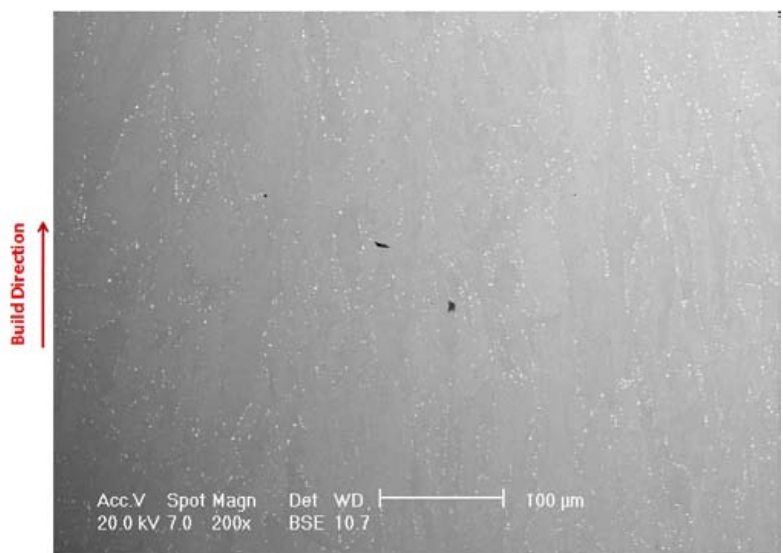

Figure 13. Laser fabricated sample following a post-fabrication HIP treatment. The internal structure appears to be crack free with only some small isolated porosity remaining.

\section{Conclusions}

This work represents the first study to assess the influence of process parameters on the development of various cracking mechanisms due to SLM of Ni-based superalloys, and also the first to map the various mechanisms as a function of the process parameters. While not all aspects of the cracking mechanisms could be studied in full detail due to the complexity of the material thermal history, nonetheless the main findings can be summarised as follows:

- Three distinctive styles of defect have been observed in the SLM fabricated samples of CM247LC: Solidification cracks, grain boundary cracks and volumetric defects or voids.

- The likely mechanism for the formation of the solidification cracks has been identified due to their unique structure showing the dendrite morphology.

- Three potential mechanisms have been identified for the formation of the grain-boundary cracks: liquation cracking, strain-age cracking (SAC) and ductility-dip cracking (DDC) - however, based on microstructural observations, SAC and DDC provide the most feasible explanations.

- The dominance of the defect styles have been linked to the process parameters of scan speed and laser power

o Solidification cracking dominant under 'highenergy' conditions

o Grain-boundary cracking dominant under 'low-energy' conditions

o Void formation occurring due to incomplete consolidation under 'very low-energy' conditions.

- A reduction in scan spacing has been shown to eliminate the occurrence of voids.

- Under higher laser power conditions a reduction in scan spacing has shown and increase in solidification cracking and is an area requiring further investigation.

- A post-fabrication HIP of the laser fabricated material has been proven effective at closing the remaining internal cracks, however, further metallurgical investigation and mechanical testing is required to show the effect of the HIP treatment compared against that in the as-fabricated condition.

\section{Acknowledgements}

The authors would like to acknowledge the support of our collaborators from ES Technology, Meggitt, MicroTurbo/Safran Group, DSTL and DGA. LNC would like to acknowledge the financial support provided by the Engineering and Physical Sciences Research Council (EPSRC) for his PhD Scholarship.

\section{References}

[1] Wu X. A review of laser fabrication of metallic engineering components and of materials. Materials Science and Technology 2007;23:631.

[2] Wu X, Mei J. Near net shape manufacturing of components using direct laser fabrication technology. Journal of Materials Processing Technology 2003;135:266.

[3] Levy GN, Schindel R, Kruth JP. Rapid manufacturing and rapid tooling with layer manufacturing (LM) technologies, state of the art and future perspectives. CIRP Annals Manufacturing Technology 2003;52:589.

[4] Conley JG, Marcus HL. Rapid Prototyping and Solid Free Form Fabrication. Journal of Manufacturing Science and Engineering, Transactions of the ASME 1997;119:B.

[5] Donachie MJ, Donachie SJ. Superalloys: A Technical Guide: ASM International, 2002. 
[6] DuPont JN, Lippold JC, Kiser SD. Welding Metallurgy and Weldability of Nickel-Base Alloys: Wiley, 2009.

[7] Kou S. Welding Metallurgy: Wiley, 2003.

[8] Dye D, Hunziker O, Reed RC. Numerical analysis of the weldability of superalloys. Acta Materialia 2001;49:683.

[9] Zhong M, Hongqing S, Wenjin L, Xiaofeng Z, Jinjiang $\mathrm{H}$. Boundary liquation and interface cracking characterization in laser deposition of Inconel 738 on directionally solidified Nibased superalloy. Scripta Materialia 2005;53:159.

[10] Sidhu RK, Ojo OA, Chaturvedi MC. Microstructural Response of Directionally Solidified Rene' 80

Superalloy to Gas-Tungsten Arc Welding. Metallurgical and Materials Transactions A (Physical Metallurgy and Materials Science) 2009;40A:150 162.

[11] Egbewande AT, Buckson RA, Ojo OA. Analysis of laser beam weldability of Inconel 738 superalloy. Materials Characterization 2010;61:569.

[12] Henderson MB, Arrell D, Larsson R, Heobel M, Marchant G. Nickel based superalloy welding practices for industrial gas turbine applications. Science and Technology of Welding \& Joining 2004;9:13.

[13] Rowe MD. Ranking the resistance of wrought superalloys to strain-age cracking. Welding Journal (Miami, Fla) 2006;85:27S

[14] Collins MG, Lippold JC. An investigation of ductility dip cracking in nickel-based filler materials - Part I. Welding Journal (Miami, Fla) 2003;82:288/S

[15] Kim IS, Choi BG, Hong HU, Yoo YS, Jo CY. Anomalous deformation behavior and twin formation of Ni-base superalloys at the intermediate temperatures. Materials Science and Engineering: A 2011;528:7149.

[16] Collins MG, Ramirez AJ, Lippold JC. An investigation of ductility-dip cracking in nickel-based weld metals - Part III. Welding Journal (Miami, Fla) 2004;83:39/S.

[17] Collins MG, Ramirez AJ, Lippold JC. An Investigation of Ductility Dip Cracking in Nickel-Based Weld Metals - Part II. Welding Journal (Miami, Fla) 2003;82:348S.

[18] Ramirez AJ, Lippold JC. High temperature behavior of Ni-base weld metal Part II - Insight into the mechanism for ductility dip cracking. Materials Science and Engineering A 2004;380:245.

[19] Ramirez AJ, Lippold JC. High temperature behavior of Ni-base weld metal Part I. Ductility and microstructural characterization. Materials Science \&amp; Engineering A (Structural Materials: Properties, Microstructure and Processing) 2004;A380:259.

[20] Young GA, Capobianco TE, Penik MA, Morris BW, McGee JJ. The mechanism of ductility dip cracking in nickelchromium alloys. Welding Journal (Miami, Fla) 2008;87:31.

[21] Liu F, Lin X, Yang G, Song M, Chen J, Huang W. Microstructure and residual stress of laser rapid formed Inconel 718 nickel-base superalloy. Optics and Laser Technology 2011;43:208

[22] Liu F, Lin X, Huang C, Song M, Yang G, Chen J, Huang $W$. The effect of laser scanning path on microstructures and mechanical properties of laser solid formed nickel-base superalloy Inconel 718. Journal of Alloys and Compounds 2011;509:4505.

[23] Chen J, Xue L, Wang S-H. Experimental studies on process-induced morphological characteristics of macro- and microstructures in laser consolidated alloys. Journal of Materials Science 2011;46:5859.
[24] Zhong M, Sun H, Liu W, Zhu X, He J. Boundary liquation and interface cracking characterization in laser deposition of Inconel 738 on directionally solidified Ni-based superalloy. Scripta Materialia 2005;53:159.

[25] Chen J, Xue L. Process-induced microstructural characteristics of laser consolidated IN-738 superalloy. Materials Science and Engineering A 2010;527:7318.

[26] Dinda GP, Dasgupta AK, Mazumder J. Laser aided direct metal deposition of Inconel 625 superalloy: Microstructural evolution and thermal stability. Materials Science and Engineering A 2009;509:98.

[27] Hussein NIS, Segal J, McCartney DG, Pashby IR. Microstructure formation in Waspaloy multilayer builds following direct metal deposition with laser and wire. Materials Science and Engineering A 2008;497:260.

[28] Li J, Wang HM. Microstructure and mechanical properties of rapid directionally solidified Ni-base superalloy Rene'41 by laser melting deposition manufacturing. Materials Science and Engineering A 2010;527:4823.

[29] Gaumann M, Bezencon C, Canalis P, Kurz W. Singlecrystal laser deposition of superalloys: Processing-microstructure maps. Acta Materialia 2001;49:1051.

[30] Das S. Physical Aspects of Process Control in Selective Laser Sintering of Metals. Advanced Engineering Materials 2003;5:701.

[31] Moat RJ, Pinkerton AJ, Li L, Withers PJ, Preuss M. Residual stresses in laser direct metal deposited Waspaloy. Materials Science and Engineering: A 2011;528:2288.

[32] Zhang C, Li L, Deceuster A. Thermomechanical analysis of multi-bead pulsed laser powder deposition of a nickelbased superalloy. Journal of Materials Processing Technology 2011;211:1478.

[33] Wu X, Wang F, Clark D. On direct laser deposited Hastelloy X: dimension, surface finish, microstructure and mechanical properties. Materials Science and Technology 2011;27:344

[34] Reed RC, Cox DC, Rae CMF. Damage accumulation during creep deformation of a single crystal superalloy at $1150 \mathrm{C}$. Materials Science and Engineering A 2007;448:88.

[35] Zhao X, Lin X, Chen J, Xue L, Huang W. The effect of hot isostatic pressing on crack healing, microstructure, mechanical properties of Rene88DT superalloy prepared by laser solid forming. Materials Science and Engineering A 2009;504:129.

[36] Kim IS, Choi BG, Seo SM, Kim DH, Jo CY. Influence of heat treatment on microstructure and tensile properties of conventionally cast and directionally solidified superalloy CM247LC. Materials Letters 2008;62:1110.

[37] Cannon-Muskegon. C-M Group Website. www.cmgroup.com, vol. 2009, 2009.

[38] Harris K, Erickson GL, Schwer RE. MAR M 247 Derivations - CM 247 LC DS Alloy, CMSX Single Crystal Alloys: Performance and Propeties. Superalloys 1984 1984:221

[39] Maldini M, Marchionni M, Nazmy M, Staubli M, Osinkolu G. Creep and fatigue properties of a directionally solidified nickel base superalloy at elevated temperature. Warrendale, PA, USA: TMS, 1996. p.327.

[40] Doherty JE, Kear BH, Giamei AF. On the origin of the ductility enhancement in Hf-doped Mar-M200. Journal of Metals 1971;23:59.

[41] Zhang J, Singer RF. Effect of Grain-Boundary Characteristics on Castability of Nickel-Base Superalloys. Metallurgical and Materials Transactions A: Physical Metallurgy and Materials Science 2004;35 A:939. 
[42] Thijs L, Verhaeghe F, Craeghs T, Humbeeck JV, Kruth J-P. A study of the microstructural evolution during selective laser melting of Ti-6Al-4V. Acta Materialia 2010;58:3303.

[43] Rasband W. ImageJ 1.34u. National institutes of health. 